\title{
Prevention of Ge Volatilization in the Chemical Treatment of Ge-Cr-Al-Ce-Sm Amorphous Alloy for the Determination of Ge by ICP-AES
}

\author{
Yûetsu DANZAKI and Kazuaki Wagatsuma \\ Institute for Materials Research, Tohoku University, 2-1-1, Katahira, Aoba, Sendai 980-8577, Japan
}

(Received December 4, 2001; Accepted April 24, 2002)

\section{Introduction}

For the dissolution procedure of Ge alloys, several mixtures of acids have been investigated: $\mathrm{HNO}_{3}-\mathrm{HF},{ }^{1-4} \mathrm{H}_{2} \mathrm{SO}_{4}-\mathrm{HNO}_{3}-\mathrm{HF},{ }^{5,6}$ and $\mathrm{HNO}_{3}$-tartaric acid. ${ }^{7}$ However, such acid mixtures cannot be applied to the dissolution of $\mathrm{Ge}$ alloys containing $\mathrm{Cr}$, due to a $\mathrm{Cr}$ stable oxide film hindering the reaction; therefore, a mixed acid containing large amounts of $\mathrm{HCl}$ should be employed for the dissolution. On the other hand, it has been reported that $\mathrm{Ge}$ easily volatilizes as $\mathrm{GeCl}_{4}$ when using aqua regia as the dissolvent. ${ }^{2}$ One must pay careful attention to the volatilization loss of Ge. Another study revealed that metallic Ge could be completely dissolved without any volatilization loss by using a mixed acid of $35 \mathrm{ml}$ of $\mathrm{HNO}_{3}$ (diluted $1+1$ ), $5 \mathrm{ml}$ of $\mathrm{HCl}$ (diluted $1+1$ ), and $1 \mathrm{~g}$ of tartaric acid as a dissolvent. However, this method is not also applied to the dissolution of $\mathrm{Ge}$ alloys containing $\mathrm{Cr}$, because $\mathrm{Ge}$ begins to volatilize when the concentration of $\mathrm{HCl}$ in the mixed acid increases.

In this paper, we report on a new method for the pretreatment of $\mathrm{Ge}$ alloys with no volatilization loss of $\mathrm{Ge}$, even with a mixed acid containing much $\mathrm{HCl}$. This developed method can be applied to the analysis of a $\mathrm{Ge}-\mathrm{Cr}-\mathrm{Al}-\mathrm{Ce}-\mathrm{Sm}$ amorphous alloy by ICP-AES.

\section{Experimental}

\section{Apparatus, reagents and solutions}

The employed Hitachi P-5200 system and its operating conditions are given in Table 1. The analytical spectral lines were determined by using a program for line selection that we have developed..$^{9} 10$

Standard reagents with purities of 99.9 to $99.999 \%$ and chemicals of analytical-reagent grade were used.

Acid mixture: $400 \mathrm{ml}$ of $\mathrm{H}_{3} \mathrm{PO}_{4}$ (diluted $1+1$ ), $400 \mathrm{ml}$ of $\mathrm{H}_{2} \mathrm{SO}_{4}$ (diluted $1+1$ ), $200 \mathrm{ml}$ of $\mathrm{HNO}_{3}, 200 \mathrm{ml}$ of $\mathrm{HCl}, 400 \mathrm{ml}$ of $\mathrm{HF}$, and $400 \mathrm{ml}$ of water were mixed.

Ce standard solution $(0.600 \mathrm{~g} / \mathrm{l}): 73.70 \mathrm{mg}$ of $\mathrm{CeO}_{2}$ that was weighed after heating in a platinum crucible was dissolved with $10 \mathrm{ml}$ of $\mathrm{HNO}_{3}$ (diluted $1+1$ ) and $5 \mathrm{ml}$ of $\mathrm{H}_{2} \mathrm{O}_{2}$; then, $10 \mathrm{ml}$ of $\mathrm{HCl}$ (diluted $1+1$ ) was added, and finally diluted to exactly $100 \mathrm{ml}$ after complete decomposition of $\mathrm{H}_{2} \mathrm{O}_{2}$ by heating.

$\mathrm{Sm}(0.400 \mathrm{~g} / \mathrm{l}), \mathrm{Al}(0.200 \mathrm{~g} / \mathrm{l})$, and $\mathrm{Cr}(0.700 \mathrm{~g} / \mathrm{l})$ standard solutions: the required amount of $\mathrm{Sm}_{2} \mathrm{O}_{3}$ that was made constant weight in the same manner as $\mathrm{CeO}_{2}$; then, metallic $\mathrm{Al}$ and metallic $\mathrm{Cr}$ were dissolved in $10 \mathrm{ml}$ of $\mathrm{HCl}$ (diluted $1+1$ ), and finally diluted to exactly $100 \mathrm{ml}$, respectively.

$\mathrm{Zn}$ solution $(5 \mathrm{~g} / \mathrm{l}): 5 \mathrm{~g}$ of metallic $\mathrm{Zn}$ was dissolved with $50 \mathrm{ml}$ of $\mathrm{HNO}_{3}$ (diluted $1+1$ ), and then diluted to $1000 \mathrm{ml}$ with water.

\section{Prevention of Ge volatilization}

When a Ge solution is prepared with a mixed acid containing small amounts of $\mathrm{HCl}$ and no $\mathrm{HF}$, it is generally observed that $\mathrm{Ge}$ is volatilized in the development of fuming $\mathrm{H}_{2} \mathrm{SO}_{4}-\mathrm{H}_{3} \mathrm{PO}_{4}$. The loss of $\mathrm{Ge}$ would be more serious if a mixed acid containing more $\mathrm{HCl}$ is required to dissolve alloys containing a large amount of $\mathrm{Cr}$. In order to prevent such volatilization of $\mathrm{Ge}$, even in the co-presence of a mixed acid having high $\mathrm{HCl}$ concentration, we developed the following procedure.

Metallic Ge of $100 \mathrm{mg}$ placed in a PTFE beaker was dissolved in a mixed acid comprising $10 \mathrm{ml}$ of $\mathrm{H}_{2} \mathrm{SO}_{4}: \mathrm{H}_{3} \mathrm{PO}_{4}: \mathrm{H}_{2} \mathrm{O}(1: 1: 2)$, 0 to $15 \mathrm{ml}$ of $\mathrm{HF}, 5 \mathrm{ml}$ of $\mathrm{HNO}_{3}$, and $15 \mathrm{ml}$ of $\mathrm{HCl}$. Moreover, a reference solution without $\mathrm{HCl}$ was prepared by using metallic $\mathrm{Ge}$ of $110 \mathrm{mg}$, and a mixed acid comprising $10 \mathrm{ml}$ of $\mathrm{H}_{2} \mathrm{SO}_{4}: \mathrm{H}_{3} \mathrm{PO}_{4}: \mathrm{H}_{2} \mathrm{O}(1: 1: 2), 2 \mathrm{ml}$ of $\mathrm{HF}$, and $10 \mathrm{ml}$ of $\mathrm{HNO}_{3}$ (diluted $1+1)$. The inside of the beaker was washed with a few $\mathrm{ml}$ of water after concentrating the solutions to almost fuming $\mathrm{H}_{2} \mathrm{SO}_{4}-\mathrm{H}_{3} \mathrm{PO}_{4}$ on a hot plate. The solutions were concentrated in the fuming operation for $5 \mathrm{~min}$. The resulting salts were dissolved in about $30 \mathrm{ml}$ of water with heating. The solution was diluted to $100 \mathrm{ml}$ after adding a $\mathrm{Zn}$ solution $(5 \mathrm{~g} / \mathrm{l})$ of $10 \mathrm{ml}$ as an internal standard for ICP-AES. The final solutions were determined by ICP-AES. To obtain results on Ge recovery, Ge solutions containing various amounts of $\mathrm{HCl}$ (from 10 to $39 \mathrm{ml}$ ) were also prepared

\section{Analysis of Ge-Cr-Al-Ce-Sm amorphous alloy}

A sample of $60 \mathrm{mg}$ placed in a PTFE beaker was dissolved with $25 \mathrm{ml}$ of the acid mixture (the same composition as that for the Ge dissolution) taken with a polypropylene pipette. The inside of the beaker was washed with a few milliliters of water after concentrating the solution to almost fuming $\mathrm{H}_{2} \mathrm{SO}_{4}-\mathrm{H}_{3} \mathrm{PO}_{4}$ on a hot plate. The solution was concentrated while keeping the fumes of $\mathrm{H}_{2} \mathrm{SO}_{4}-\mathrm{H}_{3} \mathrm{PO}_{4}$ for $5 \mathrm{~min}$. The salts were dissolved in about $30 \mathrm{ml}$ of water by heating. A $\mathrm{Zn}$ solution $(5 \mathrm{~g} / \mathrm{l})$ of $10 \mathrm{ml}$ was added as an internal standard for ICP-AES; finally, the solution was diluted to $100 \mathrm{ml}$. To determine the calibration curves of the constituent, solutions containing each element were individually prepared with standard solutions of each element and metallic Ge by the same dissolution method as the sample solution, with the exception that $10 \mathrm{ml}$ of $\mathrm{HNO}_{3}$ was added to $25 \mathrm{ml}$ of the acid mixture due to rapid dissolution of metallic Ge. 
Table 1 Instrument and operating conditions

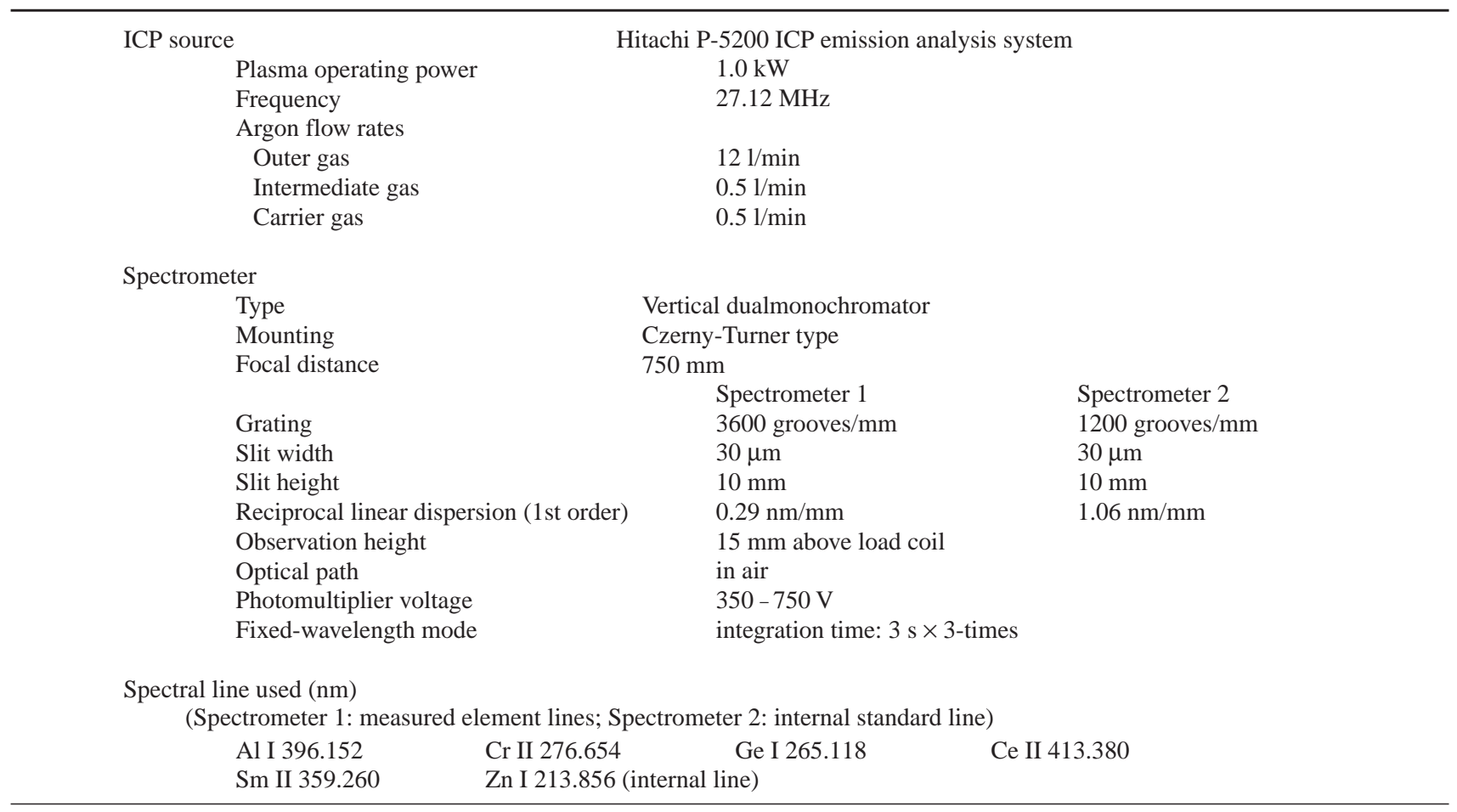

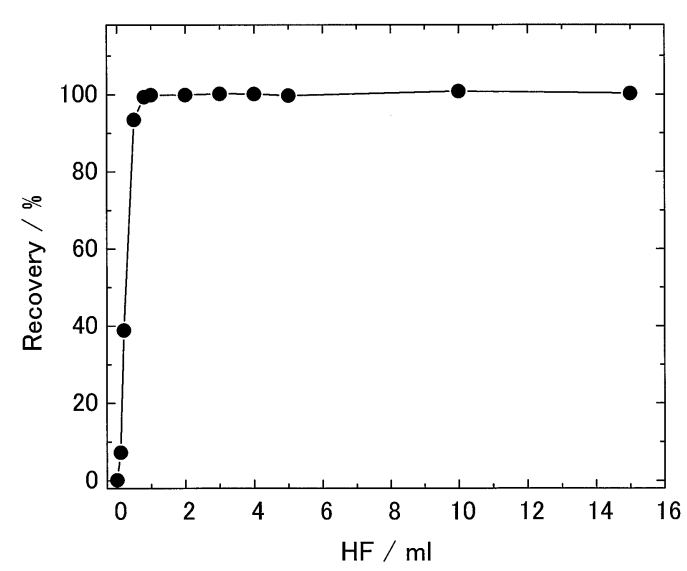

Fig. 1 Recovery of Ge when concentrated to fuming after the dissolution of metallic Ge $(100 \mathrm{mg})$ with a mixed acid of $10 \mathrm{ml}$ of $\mathrm{H}_{2} \mathrm{SO}_{4}: \mathrm{H}_{3} \mathrm{PO}_{4}: \mathrm{H}_{2} \mathrm{O}(1: 1: 2), 0$ to $15 \mathrm{ml}$ of $\mathrm{HF}, 5 \mathrm{ml}$ of $\mathrm{HNO}_{3}$ and 15 $\mathrm{ml}$ of $\mathrm{HCl}$.

\section{Results and Discussion}

\section{Prevention of Ge volatilization}

$\mathrm{Ge}$ dissolved in $\mathrm{HNO}_{3}-\mathrm{HCl}$ solutions having high $\mathrm{HCl}$ concentration would volatilize as $\mathrm{GeCl}_{4}$, and $\mathrm{Ge}$ dissolved in $\mathrm{HNO}_{3}-\mathrm{HF}$ solutions would volatilize partly as $\mathrm{GeF}_{4}$ with the progress of concentrating or evaporating to dryness. By concentrating a $\mathrm{H}_{2} \mathrm{SO}_{4}-\mathrm{HNO}_{3}-\mathrm{HF}$ solution of $\mathrm{Ge}$ (more than a few $\mathrm{mg}$ ) to the fume of $\mathrm{H}_{2} \mathrm{SO}_{4}$, rutile-type $\mathrm{GeO}_{2}$ was formed, which caused a troublesome problem because it could not be dissolved in heated water, but could be dissolved easily in HF. ${ }^{6}$ It was found by a preliminary experiment that the rutile-type $\mathrm{GeO}_{2}$ was not produced by using $\mathrm{H}_{2} \mathrm{SO}_{4}-\mathrm{H}_{3} \mathrm{PO}_{4}$ instead of $\mathrm{H}_{2} \mathrm{SO}_{4}$ alone. From these results, we considered the dissolution procedure of metallic Ge. Figure 1 shows the recovery of Ge

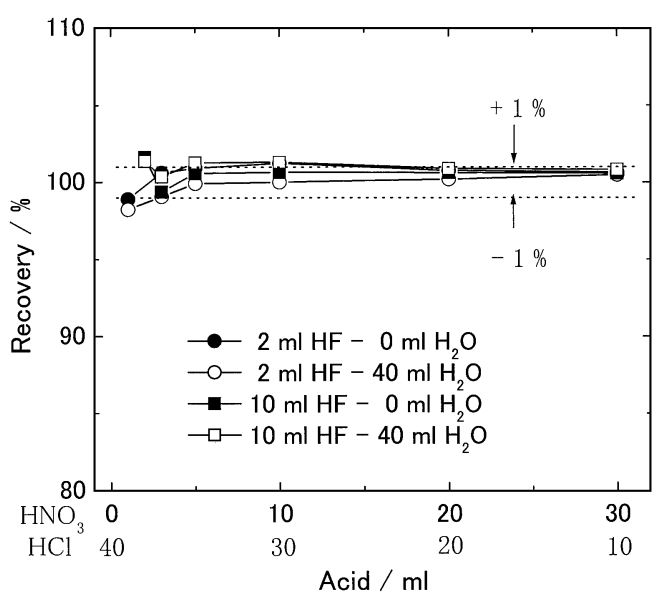

Fig. 2 Influences by $\mathrm{HCl}$ on the recovery of $\mathrm{Ge}$ when concentrated to fuming after dissolution of metallic $\mathrm{Ge}(100 \mathrm{mg})$ with a mixed acid of $10 \mathrm{ml}$ of $\mathrm{H}_{2} \mathrm{SO}_{4}: \mathrm{H}_{3} \mathrm{PO}_{4}: \mathrm{H}_{2} \mathrm{O}(1: 1: 2), 2$ or $10 \mathrm{ml}$ of $\mathrm{HF}, 1$ to $30 \mathrm{ml}$ of $\mathrm{HNO}_{3}, 39$ to $10 \mathrm{ml}$ of $\mathrm{HCl}$ and 0 or $40 \mathrm{ml}$ of water.

when $100 \mathrm{mg}$ of metallic Ge was dissolved in a mixed acid consisting of $10 \mathrm{ml}$ of $\mathrm{H}_{2} \mathrm{SO}_{4}: \mathrm{H}_{3} \mathrm{PO}_{4}: \mathrm{H}_{2} \mathrm{O}$ (1:1:2), 0 to $15 \mathrm{ml}$ of $\mathrm{HF}, 5 \mathrm{ml}$ of $\mathrm{HNO}_{3}$, and $15 \mathrm{ml}$ of $\mathrm{HCl}$, and then concentrated up to the fume of $\mathrm{H}_{2} \mathrm{SO}_{4}-\mathrm{H}_{3} \mathrm{PO}_{4}$. Ge was not volatilized in the copresence of 1 to $15 \mathrm{ml}$ of $\mathrm{HF}$ for $100 \mathrm{mg}$ of Ge. Figure 2 shows the recovery of $\mathrm{Ge}$ when $100 \mathrm{mg}$ of metallic Ge was dissolved in mixed acids consisting of $10 \mathrm{ml}$ of $\mathrm{H}_{2} \mathrm{SO}_{4}: \mathrm{H}_{3} \mathrm{PO}_{4}: \mathrm{H}_{2} \mathrm{O}(1: 1: 2)$, 2 or $10 \mathrm{ml}$ of $\mathrm{HF}, 1$ to $30 \mathrm{ml}$ of $\mathrm{HNO}_{3}, 10$ to $39 \mathrm{ml}$ of $\mathrm{HCl}$, and 0 or $40 \mathrm{ml}$ of water, and then concentrated up to the fume of $\mathrm{H}_{2} \mathrm{SO}_{4}-\mathrm{H}_{3} \mathrm{PO}_{4}$. We could find the concentration ranges of $\mathrm{HF}$ as well as $\mathrm{HCl}$ to restrain the volatilization loss of $\mathrm{Ge}$. In the presence of $2 \mathrm{ml}$ of $\mathrm{HF}$, little loss of Ge was observed in 0 to 37 $\mathrm{ml}$ of $\mathrm{HCl}$. These effects were probably because of $\left[\mathrm{GeF}_{6}\right]^{2-}$ being more stable than $\left[\mathrm{GeCl}_{6}\right]^{2-}$ or $\mathrm{GeCl}_{4}$ in aqueous solution. 
Table 2 Analytical results for a Ge amorphous alloy and synthesized solutions

\begin{tabular}{lcccccc}
\hline \multirow{2}{*}{ Sample } & \multicolumn{5}{c}{ Analytical results: wt- $\%$ for an alloy $\left(n=4\right.$, average value \pm standard deviation), and mg for mixed solutions $(n=1)^{\mathrm{a}}$} \\
\cline { 2 - 7 } & $\mathrm{Ge}$ & $\mathrm{Cr}$ & $\mathrm{Al}$ & $\mathrm{Ce}$ & $\mathrm{Sm}$ & Total \\
\hline Ge amorphous alloy & $69.43 \pm 0.22$ & $9.988 \pm 0.025$ & $3.468 \pm 0.009$ & $9.748 \pm 0.079$ & $7.601 \pm 0.030$ & $100.23 \pm 0.20$ \\
Synthesized solution A & 47.01 & 5.637 & 1.106 & 4.027 & 3.557 & 61.34 \\
& {$[47.17]$} & {$[5.635]$} & {$[1.098]$} & {$[4.075]$} & {$[3.566]$} & {$[61.54]$} \\
Synthesized solution B & 46.90 & 4.213 & 1.552 & 5.503 & 2.663 & 60.83 \\
& {$[47.14]$} & {$[4.226]$} & {$[1.537]$} & {$[5.433]$} & {$[2.675]$} & {$[61.01]$} \\
\hline
\end{tabular}

a. The numerical values in square brackets: quantities of elements taken in mixed solutions.

Consequently, the co-presence of HF enabled metallic Ge to be dissolved without any Ge loss, even by using a mixed acid having a high $\mathrm{HCl}$ concentration.

\section{Analytical results of Ge-Cr-Al-Ce-Sm amorphous alloy}

The alloy was not able to dissolve perfectly by using either a mixed acid of $40 \mathrm{ml}$ of $\mathrm{HNO}_{3}$ (diluted $1+1$ ) and $1 \mathrm{~g}$ of tartaric acid, ${ }^{7}$ or a mixed acid of $35 \mathrm{ml}$ of $\mathrm{HNO}_{3}$ (diluted $1+1$ ), $5 \mathrm{ml}$ of $\mathrm{HCl}$ (diluted 1+1), and $1 \mathrm{~g}$ of tartaric acid. ${ }^{8}$ The dissolution method developed for metallic Ge was successfully applied to a treatment of the alloy. The analytical results are shown in Table 2. Synthesized solutions A and B were prepared by adding Ce, $\mathrm{Sm}, \mathrm{Al}$, and $\mathrm{Cr}$ standard solutions to the solution where metallic Ge was dissolved with $25 \mathrm{ml}$ of the acid mixture and $10 \mathrm{ml}$ of $\mathrm{HNO}_{3}$, and treated in the same way as the sample after fuming $\mathrm{H}_{2} \mathrm{SO}_{4}-\mathrm{H}_{3} \mathrm{PO}_{4}$. Rare earth elements were precipitated as fluorides in a mixed acid containing $\mathrm{HF}$, but fuming $\mathrm{H}_{2} \mathrm{SO}_{4}-\mathrm{H}_{3} \mathrm{PO}_{4}$ could dissolve them. Based on the analytical results for each synthesized solution, the accuracy for the analysis was satisfactorily confirmed. Calibration relations were estimated using individual element solutions because the matrix matching was difficult to be employed in a routine analysis due to spectral and non-spectral interferences. ${ }^{11}$ Good results were obtained by the sequential correction method, ${ }^{12}$ which consists of corrections of the fluctuation in the emission intensities, impurities in the standard reagents, spectral interferences, non-spectral interferences, and blank values.

\section{Conclusions}

The dissolution method for Ge suggested in this study has advantageous features: no volatilization loss of $\mathrm{Ge}$ and no formation of rutile-type $\mathrm{GeO}_{2}$. The addition of $\mathrm{HF}$ is fairly effective for preventing $\mathrm{Ge}$ loss as $\mathrm{GeCl}_{4}$ in the co-presence of large amounts of $\mathrm{HCl}$, since $\mathrm{HF}$ works to make a more, stable complex of $\mathrm{Ge}$ in an aqueous solution. This method allows to use of $\mathrm{HCl}$, and therefore could be applied to the dissolution of $\mathrm{Ge}$ alloys containing $\mathrm{Cr}$. The analytical results of the Ge-Cr-Al$\mathrm{Ce}-\mathrm{Sm}$ amorphous alloy could be obtained by ICP-AES.

\section{References}

1. V. A. Oshman and V. M. Volkov, Zavod. Lab., 1961, 27, 1341.

2. M. Huseya, Bunseki Kagaku, 1963, 12, 555.

3. I. Hayashi, H. Hara, and Y. Goshi, Bunseki Kagaku, 1984, 33, T9.

4. E. Muller, R. Kucharkowski, V. Michel, and T. Schubert, Fresenius' J. Anal. Chem., 1996, 355, 267.

5. L. I. Lebedeva, Z. F. Tsyganova, and E. V. Chernyshova, Vestn. Leningr. Univ., 1982, (22), Fiz., Khim., (4), 115.

6. Y. Danzaki, Bunseki Kagaku, 1988, 37, 153.

7. Y. Danzaki, Fresenius' J. Anal. Chem., 1992, 344, 63.

8. T. Shoji, Y. Danzaki, T. Ashino, H. Konno, and K. Makabe, Bunseki Kagaku, 2000, 49, 709.

9. Y. Danzaki, K. Takada, K. Wagatsuma, and M. Oku, Fresenius' J. Anal. Chem., 1998, 361, 410.

10. Y. Danzaki, K. Takada, K. Wagatsuma, and M. Oku, Fresenius' J. Anal. Chem., 1999, 364, 549.

11. J. Tan, J. Wang, J. Ma, and X. Chen, Yejin Fenxi, 1991, $11(5), 48$

12. Y. Danzaki, K. Wagatsuma, T. Shoji, and K. Yoshimi, Fresenius' J. Anal. Chem., 2001, 369, 184. 